\section{Salmonella prevalence and microbiological contamination of pig carcasses and slaughterhouse environment}

\author{
Francesca Piras, ${ }^{1}$ Federica Fois, ${ }^{1}$ \\ Roberta Mazza, ${ }^{1}$ Miriam Putzolu, ${ }^{1}$ \\ Maria Luisa Delogu, ${ }^{2}$ Pier Giorgio Lochi, ${ }^{3}$ \\ Sergio Pino Pani, ${ }^{3}$ Rina Mazzette ${ }^{1}$ \\ 'Dipartimento di Medicina Veterinaria, \\ Università di Sassari; ${ }^{2}$ ASL 1, Sassari; \\ ${ }^{3}$ ASL 6, Sanluri (VS), Italy
}

\section{Abstract}

In seven EC swine abattoirs Salmonella prevalence (ISO 6579/2002) and serotypes of 25 piglets, 61 finishing pigs (lymph nodes, colon content, carcass and liver surface) and slaughterhouse environments (scalding water, surfaces in contact with meat and not in contact with meat) were investigated. Moreover, aerobic colony count [total viable count (TVC); ISO 4833] and Enterobacteriaceae (ISO 215282) of piglets and finishing pigs' carcasses were evaluated, and the results compared with EU process hygiene criteria (Reg. EC 2073/2005). Salmonella was not isolated in any of the piglets samples. Prevalence differed between slaughterhouses $(\mathrm{P}<0.5)$, and Salmonella was isolated from 39 of 244 samples of finishing slaughtered pigs (15.9\%) and from 4 of 45 environmental samples (8.9\%). In pig samples, carcasses showed the highest prevalence (18\%) followed by colon content (14.8\%), lymph nodes (13\%) and liver (1.6\%). $S$. Anatum was the most prevalent serotype (71.8\%), followed by $S$. Derby $(33.3 \%), S$. Bredeney (5\%) and $S$. Holcomb (2.5\%). Between environmental samples, $S$. Anatum (50\%), $S$. Bredeney and $S$. Derby (25\%) were identified. Total viable mean counts ( $\log _{10}$ $\mathrm{CFU} / \mathrm{cm}^{2}$ ) of carcass surfaces ranged from 4.6 and 5.7 for piglets, and from 4.6 and 5.9 for finishing pigs, while Enterobacteriaceae ranged between 1.1 and 5 for piglets and between 2.1 and 5.3 for finishing pigs. These results were not in compliance with EU performance criteria. Total aerobic viable counts and Enterobacteriaceae mean levels of environmental samples appeared critical, particularly referred to surfaces in contact with meat (splitting equipment) and indicated an inadequate application of good manufacturing and hygiene practices during slaughtering and sanitisation.

\section{Introduction}

The food safety legislation in the European Union (EU) regulates the food chain and sets down specific rules for food of animal origin. The food businness operators (FBOs) have the primary responsibility of ensuring food safety. At slaughterhouse, the implementation of good hygiene practice and procedures based on hazard analysis and critical control point (HACCP) principles are essential to prevent microbial carcass contamination in order to ensure health protection and meat safety (Lindblad and Berking, 2013). Microbiological data are necessary for the implementation and mainteinance of HACCP-based systems (Zweifel $e t$ al., 2005). For microbiological analyses of carcass samples, performance criteria are given in Commission Regulation (EC) No. 2073/2005 that sets out performance criteria for total viable counts (TVC), Enterobacteriaceae and Salmonella as process hygiene indicators. Salmonella detection at slaughterhouse can also be useful data for surveillance plans aimed to monitor the pig production chain (Nauta et al., 2013). According to the Regulation (EC) No. 2160/2003 EU Member States (MS) are required to take effective measures to control Salmonella in different species, including pigs, in order to reduce the incidence of human salmonellosis. During the last two decades, pork has been recognised as a common food vehicle for human exposure (Mannion et al., 2012) and many MS (e.g., United Kingdom, Sweden, Germany, and Belgium) have already set out Salmonella surveillance and control programmes for pigs and pork (Arguello et al., 2012). However, most MS have not yet implemented such programmes, including Italy. Each MS has to consider whether interventions should be set at farm and/or abattoir level (De Busser et al., 2013) and different strategies could be chosen depending on the country-specific pig industry, the Salmonella herd-status and the slaughterhouse structure (Baptista et al., 2010). Anyway, the abattoir remains the most appropriate stage of the food chain for the evaluation of the carriage of Salmonella and other zoonotic agents by farm animals (Bonardi et al., 2013). Based on a recent EFSA report, $10.3 \%$ of slaughter pigs were found to be infected with Salmonella in lymph nodes and $8.3 \%$ of the carcasses were contaminated too (EFSA, 2008). Pig carcass contamination can result from the intestinal carriage of Salmonella in the pig itself, but also from contact with other contaminated carcasses or surfaces at slaughterhouse (Botteldoorn et al., 2003). Hygiene varies between abattoirs and could have an impact on carcass contamination (McDowell et al., 2007).

Aim of this study was to obtain data about
Correspondence: Francesca Piras, Settore di Ispezione degli Alimenti di Origine Animale, Dipartimento di Medicina Veterinaria, Università di Sassari, via Vienna 2, 07100 Sassari. Tel. +39.079.229447 - Fax: +39.079.229458. E-mail: fpiras@uniss.it

Key words: Salmonella, Pig slaughterhouse, Carcass, Process hygiene criteria.

Conflict of interests: the authors declare no potential conflict of interests.

Received for publication: 17 July 2014 Revision received: 22 September 2014. Accepted for publication: 22 September 2014.

This work is licensed under a Creative Commons Attribution 3.0 License (by-nc 3.0).

(C) Copyright F. Piras et al., 2014

Licensee PAGEPress, Italy

Italian Journal of Food Safety 2014; 3:4581

doi:10.4081/ijfs.2014.4581

the prevalence and the serotypes of Salmonella in piglets and finishing pigs at slaughterhouse. Moreover, the microbiological contamination of piglets and finishing pigs' carcasses was evaluated and the results compared with EU process hygiene criteria.

\section{Materials and Methods}

The study was carried out in seven EC swine abattoirs (sA, sB, sC, sD, sE, sF, sG) in Sardinia. Samples were collected from 25 piglets and 61 finishing pigs during ten sampling days (SD). $\mathrm{sA}, \mathrm{sB}$ and $\mathrm{sF}$ were visited two times (SD1 and $\mathrm{SD} 2) . \mathrm{sC}, \mathrm{sD}, \mathrm{sE}$ and $\mathrm{sG}$ were visited once. During the first visit at $\mathrm{sA}, \mathrm{sB}$ and at $\mathrm{sC}$, specimens were collected from piglets (approximately $15 \mathrm{~kg}$ in weight) coming from local farms. During SD2 at $\mathrm{sA}$ and $\mathrm{sB}$ and at $\mathrm{sD}, \mathrm{sE}, \mathrm{sF}$ and $\mathrm{sG}$, specimens were collected from finishing pigs (100-120 kg in weight). Pigs slaughtered at $\mathrm{sA}, \mathrm{sB}, \mathrm{sD}, \mathrm{sE}$, and $\mathrm{sG}$ and during $\mathrm{SD} 1$ at $\mathrm{sF}$ were from local farms. Pigs slaughtered during SD2 at $\mathrm{sF}$ were from Spain.

\section{Salmonella isolation and serotyping}

Samples were collected as previously described (Piras et al., 2011). From each pig, after dressing and before chilling, samples of lymph nodes, colon content, carcass surface and liver surface were collected. Overall, 344 samples were collected from piglets and adult pigs (86 lymph-nodes, 86 colon content, 86 carcass surface and 86 liver surface). Moreover, the following samples were collected from slaughterhouse environments: scalding water with a sterile collection tube (10 samples), surfaces in 
contact with meat (9 samples of carcass splitting equipment and 9 of dehairing equipment) and surfaces not in contact with meat (9 samples collected from the wall surface of the dirty zone, 9 from the wall surface of the clean zone and 9 from drains) with a sterile sponge. For the isolation of Salmonella, the ISO method $6579 / 2002$ (ISO, 2002) modified according to EFSA report on Risk assessment and mitigation opinion of Salmonella in pig production was used. Presumptive colonies were submitted to phenotypic identification with the API ID 32E system (bioMérieux, Marcy l'Etoile, France). One colony from each positive sample (44 in total) was selected and sent to the laboratories of the Centro Nazionale di Referenza per le Salmonellosi in Legnaro (Padua, Italy), serotyped by agglutination tests with specific 0 and $\mathrm{H}$ antisera (Staten Serum Institute, Copenhagen, Denmark) and classified according to the Kauffmann-White scheme.

\section{Process hygiene criteria evaluation}

Each carcass was sampled after dressing and before chilling by sponge, according to ISO 17604 (Reg. EC No.2073/2005) at cheek, belly, back and ham sites in order to evaluate the process hygiene criteria stated by Reg. EC No.2073/2005. Therefore, samples were analysed for aerobic colony count (ISO 4833; ISO, 2003) and Enterobacteriaceae (ISO 215282) and the results expressed in $\log _{10}$ colony forming units/ $\mathrm{cm}^{2}\left(\mathrm{CFU} / \mathrm{cm}^{2}\right)$. Process hygiene criteria were also evaluated in samples collected from surfaces in contact and not in contact with meat described above. An analysis of variance (ANOVA) using the general linear model (GLM) procedure was performed for all considered variables, and when F-values were significant at the $\mathrm{P}<0.05$ level, mean differences were separated by the least significant differences (LSD).

\section{Results}

\section{Salmonella prevalence}

Salmonella was not isolated in any of the samples collected from piglets, while it was isolated from 40 of 244 samples of finishing slaughtered pigs (16.4\%) and from 4 of 45 environmental samples (8.9\%). Table 1 shows Salmonella prevalence per slaughterhouse in finishing pigs and environmental samples. Salmonella prevalence was different among slaughterhouses $(\mathrm{P}<0.5)$. sF showed the highest prevalence in pig samples (46.2\%), followed by sA (6.25\%) and sG (2.5\%). Salmonella was not isolated in any of the pig samples collected at $\mathrm{sB}, \mathrm{sD}$ and $\mathrm{sE}$. With regard to the sampling site, the highest prevalence was observed in carcasses (18\%), followed by colon content (14.8\%), lymph nodes (13\%) and liver (1.6\%). At sF, 12 pigs were found to carry Salmonella in lymph nodes and/or colon content, and in 9 of these pigs the pathogen was also isolated from the carcass. As regard to environmental samples, Salmonella was isolated at $\mathrm{sF}$ and $\mathrm{sG}$ with an overall prevalence of $11 \%(3 / 27)$ in samples of surfaces not in contact with meat and 5.5\% (1/18) in samples of surfaces in contact with meat. At $\mathrm{sF}$, Salmonella was isolated in one sample of drain water and in one of the wall surface of the dirty zone. At sG, Salmonella was isolated in one sample of drain water and in one sample of carcass splitter equipment.

\section{Salmonella serotypes}

A total of 44 Salmonella isolates were detected and 4 serotypes identified. Table 2 shows the detail of the Salmonella serotypes isolated from the pig and environmental samples per slaughterhouse and SD. $S$. Anatum was the most prevalent serotype in pig samples accounting for $71.8 \%$ (28/44) of all isolates. Other Salmonella serotypes isolated from the pig samples were $S$. Derby $(33.3 \%, 13 / 44), S$. Bredeney $(5 \%, 2 / 39)$ and $S$. Holcomb $(2.5 \%$, $1 / 39$ ). At sA, $S$. Derby was isolated from a sample of colon content, while $S$. Holcomb from the liver surface of one pig. At sF, during SD1 and SD2, Salmonella was detected in all pig sample type and also in samples of surfaces in contact with meat. All the isolates detected during SD1 were $S$. Anatum, while the isolates detected during SD2 were $S$. Derby. At $\mathbf{s G}, S$. Bredeney was detected from a sample of carcass surface and from a sample of drain, while $S$. Anatum from a sample of carcass splitting equipment.

Three different serotypes were identified among 4 isolates detected from the environmental samples: $S$. Anatum $(50 \%, 2 / 4), S$. Bredeney and $S$. Derby $(25 \%, 1 / 4)$.

\section{Process hygiene criteria evaluation}

Table 3 shows TVC and Enterobacteriaceae mean levels $\left(\log _{10} \mathrm{CFU} / \mathrm{cm}^{2}\right.$; mean $\left.\pm \mathrm{sd}\right)$ of piglets and finishing pigs' carcass surface.

Carcass surface TVC regarding piglets carcass samples $\mathrm{sC}$ showed the highest levels $(5.74 \pm 0.56)$, while lower mean counts were recorded at $\mathrm{sA}(5.00$, with a prevalence of $10 \%)$ and $\mathrm{sB}(4.62 \pm 0.45)$. In finishing pigs' carcass surface samples higher mean values were recorded in all the slaughterhouses, in comparison to piglets. $\mathrm{sB}$ showed the highest levels $(6.35 \pm 0.12)$. Mean counts $>5 \log$ were registered at $\mathrm{sG}(5.94 \pm 0.39), \mathrm{sD}(5.92 \pm 0.32), \mathrm{sF}$ $(5.87 \pm 0.76)$ and sA $(5.27 \pm 0.79)$. Significantly $(\mathrm{P}<0.5)$ lower levels were noticed at $\mathrm{sE}$ $(4.69 \pm 0.48)$.

\section{Carcass surface Enterobacteriaceae}

sC showed significantly $(\mathrm{P}<0.1)$ higher levels $(5.09 \pm 0.87)$ in carcass surface samples collected from piglets with respect to the other slaughterhouses. Lower mean counts were registered at $\mathrm{sB}(1.19 \pm 1.31)$, with a prevalence of $40 \%$. As regard to finishing pigs carcass surface samples, sD showed the highest levels $(5.34 \pm 0.56)$, followed by $\mathrm{sF}(4.85 \pm 1.80)$. Mean counts $>3 \log$ were noticed at $\mathrm{sG}(3.85 \pm 1.40)$, $\mathrm{sA}(3.80 \pm 0.27)$ and $\mathrm{sB}(3.57 \pm 0.81)$. The lowest levels were noticed at $\mathrm{sE}(2.17 \pm 1.25)$.

Table 4 shows TVC and Enterobacteriaceae mean levels $\left(\log _{10} \mathrm{CFU} / \mathrm{cm}^{2}\right.$; mean \pm sd) of surfaces in contact and surfaces not in contact with meat.

\section{Environment total viable count}

As regard to samples collected from contact surfaces with meat $\mathrm{sF}$ showed the highest lev-

Table 1. Salmonella prevalence in adult pigs and environmental samples per slaughterhouse.

\begin{tabular}{|c|c|c|c|c|c|c|}
\hline \multirow[t]{2}{*}{ Samples } & \multicolumn{6}{|c|}{ Abattoirs } \\
\hline & sA & sB & $\mathrm{sD}$ & sE & $\mathrm{sF}$ & sG \\
\hline \multicolumn{7}{|l|}{ Pig } \\
\hline Lymph nodes & $-(0 / 8)$ & $-(0 / 3)$ & $-(0 / 10)$ & $-(0 / 10)$ & $40(8 / 20)$ & $(0 / 10)$ \\
\hline Colon content & $12.5(1 / 8)$ & $-(0 / 3)$ & $-(0 / 10)$ & $-(0 / 10)$ & $40(8 / 20)$ & $(0 / 10)$ \\
\hline Carcass & $-(0 / 8)$ & $-(0 / 3)$ & $-(0 / 10)$ & $-(0 / 10)$ & $55(11 / 20)$ & $10(1 / 10)$ \\
\hline Liver & $12.5(1 / 8)$ & $-(0 / 3)$ & $-(0 / 10)$ & $-(0 / 10)$ & $50(10 / 20)$ & $(0 / 10)$ \\
\hline Total & 32 & 12 & 40 & 40 & 80 & 40 \\
\hline \multicolumn{7}{|l|}{ Environmental } \\
\hline $\mathrm{CM}$ & $-(0 / 4)$ & $-(0 / 2)$ & $-(0 / 2)$ & $-(0 / 2)$ & $-(0 / 4)$ & $50(1 / 2)$ \\
\hline $\mathrm{NCM}$ & $-(0 / 6)$ & $-(0 / 3)$ & $-(0 / 3)$ & $-(0 / 3)$ & $33(2 / 6)$ & $33(1 / 3)$ \\
\hline Scalding water & $-(0 / 1)$ & $-(0 / 1)$ & $-(0 / 1)$ & $-(0 / 1)$ & - & $-(0 / 1)$ \\
\hline Total & 11 & 6 & 6 & 6 & 10 & 6 \\
\hline
\end{tabular}

-, not detected; CM, surfaces in contact with meat; NCM, surfaces not in contact with meat. The number of positive samples out of the total is reported in brackets. 
els $(6.31 \pm 0.86 \log )$, particularly in samples of dehairing equipment, followed by $\mathrm{sB}$ $(5.87 \pm 0.96 \log )$. The lowest levels were recorded at $\mathrm{sA}(3.22 \pm 2.8 \mathrm{log})$. Also for surfaces not in contact with meat samples, sF showed the highest levels $(>6 \log$ ). Slightly lower counts were recorded at $\mathrm{sE}$ and $\mathrm{sC}(5.66 \pm 0.71$ and $4.76 \pm 1.79 \log$ respectively). The others abattoirs showed levels ranging from 2.8 to 4 .

\section{Environment Enterobacteriaceae}

As for samples collected from surfaces in contact with meat, $\mathrm{sF}$ showed the highest mean counts $(5.80 \pm 0.9)$. Levels of $2.62 \pm 2.2$ and $3.42 \pm 0.98$ were registered at $\mathrm{sA}$ and $\mathrm{sB}$, respectively. For surfaces in contact with meat samples at $\mathrm{sE}$ and $\mathrm{sF}$ mean levels $>5.5 \log$ were detected. The other abattoirs showed significantly $(\mathrm{P}<0.1)$ lower counts, ranging from 1.5 and 2.7.

\section{Discussion}

This study showed a large variability in Salmonella prevalence among the different slaughterhouses, in accordance with other studies, showing that contamination depends on the slaughterhouse (hygienic parameters and qualification of personnel), the sampling day and the origin and the number of infected pigs delivered during the same day (Botteldoorn et al., 2003). The importance of healthy pigs, carrying human pathogenic Salmonella strains, is already well known (Fosse et al., 2009). As said, in our study, at $\mathrm{sF}$ Salmonella isolates belonging to the same serotype were detected during two different SD in lymph nodes and/or colon content and from the carcass. In addition, the same serotypes were detected from the liver surface and from environmental samples, namely the carcass splitter equipment. These results indicate a presumable cross-contamination of Salmonella on carcasses and slaughterhouse environment. However, further analysis (e.g. through pulsed field gel electrophoresis) is needed in order to characterise the isolates and better understand the Salmonella contamination routes. Our results on Salmonella prevalence in colon content samples of finishing pigs (14.8\%) were slightly lower than those detected in other studies that showed levels of $21.9 \%$ (Bonardi et al., 2013) and 24.9\% (Visscher et al., 2011).

In our study, differences regarding serotypes detected at $\mathrm{sF}$ were noticed in relation to the origin (Spain and local) of the finishing pigs. During SD1, all the Salmonella isolates were identified as $S$. Anatum, which is quite common in pigs slaughtered in Spain

Table 2. Salmonella serotypes distribution per slaughterhouse, sampling day and sample.

\begin{tabular}{|c|c|c|c|c|c|c|c|c|}
\hline Slaughterhouse & SD & Colon content & Lymph node & Carcass & Liver & \multicolumn{2}{|c|}{ Surfaces } & Total \\
\hline sA & 2 & Derby (1) & & & Holcomb (1) & & 2 & \\
\hline$s F$ & 1 & Anatum (6) & Anatum (5) & Anatum (10) & Anatum (5) & & Anatum (1) & 27 \\
\hline & 2 & Derby (2) & Derby (3) & Derby (1) & Derby (5) & & Derby (1) & 12 \\
\hline$s \mathrm{~s}$ & 1 & & & Bredeney (1) & & Bredeney (1) & Anatum (1) & 2 \\
\hline Total & & 9 & 8 & 12 & 11 & 1 & 3 & 44 \\
\hline
\end{tabular}

SD, sampling day; NCM, surfaces not in contact with meat; CM, surfaces in contact with meat. The number of isolates is reported in brackets.

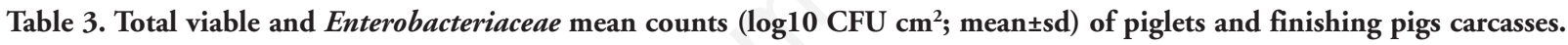

\begin{tabular}{|c|c|c|c|c|}
\hline \multirow[t]{2}{*}{ Slaughterhouse } & \multicolumn{2}{|c|}{ Piglets } & \multicolumn{2}{|c|}{ Finishing pigs } \\
\hline & TVC & Enterobacteriaceae & TVC & Enterobacteriaceae \\
\hline sA & $5.00 \pm 0(10)^{\mathrm{B}}$ & - & $5.27 \pm 0.79^{\mathrm{B}}$ & $3.80 \pm 0.27^{\mathrm{B}}$ \\
\hline sB & $4.62 \pm 0.45^{\mathrm{A}}$ & $1.19 \pm 1.31(40)^{\mathrm{B}}$ & $6.35 \pm 0.12^{\mathrm{A}}$ & $3.57 \pm 0.81^{\mathrm{ABC}}$ \\
\hline $\mathrm{sC}$ & $5.74 \pm 0.56^{\mathrm{A}}$ & $5.09 \pm 0.87^{\mathrm{A}}$ & nd & nd \\
\hline sD & nd & nd & $5.92 \pm 0.32^{\mathrm{A}}$ & $5.34 \pm 0.87^{\mathrm{A}}$ \\
\hline$s E$ & nd & nd & $4.69 \pm 0.48^{\mathrm{c}}$ & $2.17 \pm 1.25(80)^{\mathrm{C}}$ \\
\hline sF & nd & nd & $5.87 \pm 0.76^{\mathrm{A}}$ & $4.85 \pm 1.80^{\mathrm{AB}}$ \\
\hline$s G$ & nd & nd & $5.94 \pm 0.39^{A}$ & $3.85 \pm 1.40^{\mathrm{B}}$ \\
\hline
\end{tabular}

TVC, total viable count; -, not detected; nd, not determined. Prevalence (\%), if different from 100, is reported in brackets. ${ }^{A-C}$ Means within columns with different letters are significantly different ( $<<0.01$; $\mathrm{P}<0.1$; $\mathrm{P}<0.5)$.

Table 4. Total viable and Enterobacteriaceae mean counts $\left(\log _{10} \mathrm{CFU} / \mathrm{cm}^{2}\right.$; mean $\left.\pm \mathrm{sd}\right)$ of environmental samples.

\begin{tabular}{|c|c|c|c|c|}
\hline \multirow{2}{*}{ Slaughterhouse } & \multicolumn{2}{|c|}{ TVC } & \multicolumn{2}{|c|}{ Enterobacteriaceae } \\
\hline & CM & NCM & CM & $\mathrm{NCM}$ \\
\hline sA & $3.22 \pm 2.8(66)^{\mathrm{B}}$ & $3.33 \pm 2.7(66)^{\mathrm{B}}$ & $2.62 \pm 2.2(66)^{\mathrm{B}}$ & $2.11 \pm 3.01(33)^{\mathrm{B}}$ \\
\hline sB & $5.87 \pm 0.96(75)^{\mathrm{AB}}$ & $2.82 \pm 3.22(50)^{\mathrm{B}}$ & $3.42 \pm 0.98(75)^{\mathrm{AB}}$ & $1,59 \pm 2.4(50)^{\mathrm{B}}$ \\
\hline $\mathrm{sC}$ & $4.58 \pm 2.98^{\mathrm{AB}}$ & $4.76 \pm 1.79^{\mathrm{AB}}$ & $4 \pm 1.41^{\mathrm{AB}}$ & $2,48 \pm 0.00(66)^{\mathrm{B}}$ \\
\hline sD & $4.5 \pm 1.76^{\mathrm{AB}}$ & $4.02 \pm 1.82^{\mathrm{AB}}$ & $4 \pm 0.56^{\mathrm{AB}}$ & $2,75 \pm 2.63(66)^{\mathrm{B}}$ \\
\hline$s \mathrm{E}$ & $3.50 \pm 3.13(50)^{\mathrm{AB}}$ & $5.12 \pm 2.17^{\mathrm{AB}}$ & $5.65(66)^{\mathrm{AB}}$ & $6.23(66)^{\mathrm{AB}}$ \\
\hline$s F$ & $6.31 \pm 0.86(66)^{\mathrm{A}}$ & $6.12 \pm 1.13^{\mathrm{A}}$ & $5.80 \pm 0.9(66)^{\mathrm{A}}$ & $6.29 \pm 0.71(83)^{\mathrm{A}}$ \\
\hline $\mathrm{sG}$ & $4.85^{\mathrm{AB}}$ & $5.66 \pm 0.71^{\mathrm{AB}}$ & $3.64 \pm 0.79^{\mathrm{AB}}$ & $5.97 \pm 0.65^{\mathrm{B}}$ \\
\hline
\end{tabular}

TVC, total viable count; CM, surfaces in contact with meat; NCM, surfaces not in contact with meat. Prevalence (\%), if different from 100, is reported in brackets. ${ }^{\mathrm{AB}} \mathrm{B}$ Means within columns with different letters are significantly different $(\mathrm{P}<0.01 ; \mathrm{P}<0.1 ; \mathrm{P}<0.5)$. 
(Arguello et al., 2012, 2013; Hernandez et al., 2013) and in other European countries (De Busser et al., 2011; McDowell et al., 2007). On the contrary, during SD2 all the isolates were identified as $S$. Derby, which is one of the most common serovar detected in slaughtered pigs, in accordance with EFSA report (EFSA, 2013) and a number of studies carried out in Italy, the rest of Europe (Bonardi et al., 2013; De Busser et al., 2011) and also in Sardinia (Piras et al., 2011). Furthermore, $S$. Derby is between the 10 most reported serotypes in confirmed cases of human salmonellosis (EFSA, 2013), whereas $S$. Anatum has not been linked to cases of human salmonellosis.

Salmonella was not isolated in any of the samples collected from piglets. Not many data are available on Salmonella prevalence in piglets. In a study carried out by Funk et al. (2004) a very low prevalence - between 0.5 and 0.7 in fecal samples - was detected. An investigation conducted at farm showed Salmonella prevalence of blood sera samples of piglets/weaners $>20 \%$. However, Salmonella was detected only in a single case in the pooled faecal samples taken from the same pens (Nowak et al., 2007).

Total viable mean counts $\left(\log _{10} \mathrm{CFU} / \mathrm{cm}^{2}\right)$ of carcass surfaces ranged from 4.6 and 5.7 for piglets, and from 4.6 and 5.9 for finishing pigs. Such levels are higher than those detected by other studies. Bolton et al. (2002), in a smallscale slaughterhouse, registered level accounting between 4.5 and $4.7 \mathrm{log}$. In Switzerland, Zweifel et al. (2008) obtained TVC mean counts that averaged out at $3.3 \mathrm{log}$. Enterobacteriaceae mean counts ranged between 1.1 and 5 for piglets, with a prevalence accounting between 40 and $100 \%$. As for finishing pigs are concerned, mean levels ranged between 2.1 and $5.3 \mathrm{log}$, with a prevalence between 66 and $80 \%$.

\section{Conclusions}

The majority of TVC and Enterobacteriaceae results were not in compliance with performance criteria of Reg. (EC) 2073/2005. The high carcass contamination levels indicated that a detailed analysis of the slaughtering process, including microbiological data, is necessary, also considering that carcasses may be contaminated despite the absence of visible contamination (Arguello et al., 2013).

Total viable counts and Enterobacteriaceae mean levels of environmental samples appeared to be critical, particularly referred to surfaces in contact with meat (splitting equipment). At sF, TVC and Enterobacteriaceae counts indicated an inadequate application of good manufacturing and hygiene practices during slaughtering and sanitisation.

\section{References}

Arguello H, Carvajal A, Collazos JA, García-Feliz C, Rubio P, 2012. Prevalence and serovars of Salmonella enterica on pig carcasses, slaughtered pigs and the environment of four Spanish slaughterhouses. Food Res Int 45:905-12.

Arguello H, Sørensen G, Carvajal A, Baggesen DL, Rubio P, Pedersen K, 2013. Prevalence, serotypes and resistance patterns of Salmonella in Danish pig production. Res Vet Sci 95:334-42.

Baptista FM, Dahl J, Nielsen LR, 2010. Factors influencing Salmonella carcass prevalence in Danish pig abattoirs. Prev Vet Med 95:231-8.

Bolton DJ, Pearce RA, Sheridan JJ, Blair IS, McDowell DA, Harrington D, 2002. Washing and chilling as critical control points in pork slaughter hazard analysis and critical control point (HACCP) systems. J Appl Microbiol 92:893-902.

Bonardi S, Bassi L, Brindani F, D'Incau M, Barco L, Carra E, Pongolini S, 2013. Prevalence, characterization and antimicrobial susceptibility of Salmonella enterica and Yersinia enterocolitica in pigs at slaughter in Italy. Int J Food Microbiol 163:248-57.

Botteldoorn N, Heyndrickx M, Rijpens N, Grijspeerdt K, Herman L, 2003. Salmonella on pig carcasses: positive pigs and cross contamination in the slaughterhouse. J Appl Microbiol 95:891-903.

De Busser EV, De Zutter L, Dewulf J, Houf K, Maes D, 2013. Salmonella control in live pigs and at slaughter. Vet J 196:20-7.

De Busser EV, Maes D, Houf K, Dewulf J, Imberechts H, Bertrand S, De Zutter L, 2011. Detection and characterization of Salmonella in lairage, on pig carcasses and intestines in five slaughterhouses. Int $\mathrm{J}$ Food Microbiol 145:279-86.

EFSA, 2008. Report of the task force on zoonoses data collection on the analysis of the baseline survey on the prevalence of Salmonella in slaughter pigs. Part A. EFSA J 135:1-111.

EFSA, 2013. The European Union summary report on trends and sources of zoonoses, zoonotic agents and food-borne outbreaks in 2011. EFSA J 11:3129.

Fosse J, Seegers H, Magras C, 2009. Prevalence and risk factors for bacterial food-borne zoonotic hazards in slaughter pigs: a review. Zoonoses Public Hlth 56:429-54.

Funk J, Gebreyes AW, 2004. Risk factors associated with Salmonella prevalence on swine farms. J Swine Health Prod 12:246-51.

Hernández M, Gómez-Laguna J, Luque I, HerreraLeón S, Maldonado A, Reguillo L, Astorga RJ, 2013. Salmonella prevalence and characterization in a free-range pig processing plant: tracking in trucks, lairage, slaughter line and quartering. Int J Food Microbiol 162:48-54.
ISO, 2003. Microbiology of food and animal feeding stuffs: horizontal method for the enumeration of microorganisms. Colony-count technique at $30^{\circ} \mathrm{C}$. ISO Norm 4833:2003. International Standardization Organization ed., Geneva, Switzerland.

ISO, 2004. Microbiology of food and animal feeding stuffs: horizontal method for the detection of Salmonella. ISO Norm 6579:2004. International Standardization Organization ed., Geneva, Switzerland.

Lindblad M, Berking C, 2013. A meat control system achieving significant reduction of visible faecal and ingesta contamination of cattle, lamb and swine carcasses at Swedish slaughterhouses. Food Control 30:101-5.

Mannion C, Fanning J, McLernon J, Lendrum L, Gutierrez M, Duggan S, Egan J, 2012. The role of transport, lairage and slaughter processes in the dissemination of Salmonella spp. in pigs in Ireland. Food Res Int 45:871-9.

McDowell SW, Porter R, Madden R, Cooper B, Neill SD, 2007. Salmonella in slaughter pigs in Northern Ireland: prevalence and use of statistical modelling to investigate sample and abattoir effects. Int $\mathrm{J}$ Food Microbiol 118:116-25.

Nauta M, Barfod K, Hald T, Sørensen AH, Emborg H-D, Aabo S, 2013. Prediction of Salmonella carcass contamination by a comparative quantitative analysis of $\mathrm{E}$. coli and Salmonella during pig slaughter. Int J Food Microbiol 166:231-7.

Nowak B, von Müffling T, Chaunchom S, Hartung $\mathrm{J}, 2007$. Salmonella contamination in pigs at slaughter and on the farm: a field study using an antibody ELISA test and a PCR technique. Int J Food Microbiol 115:259-67.

Piras F, Brown D, Meloni D, Mureddu A, Mazzette $\mathrm{R}, 2011$. Investigation of Salmonella enterica in Sardinian slaughter pigs: prevalence, serotype and genotype characterization. Int J Food Microbiol 151:201-9.

Visscher CF, Klein G, Verspohl J, Beyerbach M, Stratman-Selke J, Kamphues J, 2011. Serodiversity and serological as well as cultural distribution of Salmonella on farms and in abattoirs in Lower Saxony, Germany. Int $\mathbf{J}$ Food Microbiol 146:44-51.

Zweifel C, Baltzer D, Stephan R, 2005. Microbiological contamination of cattle and pig carcasses at five abattoirs determined by swab sampling in accordance with EU Decision 2001/471/EC. Meat Sci 69:559-66.

Zweifel C, Fischer R, Stephan R, 2008. Microbiological contamination of pig and cattle carcasses in different small-scale Swiss abattoirs. Meat Sci 78:225-31. 